\title{
Exploration of a resilience intervention among women with disabilities: an examination of two case studies
}

\begin{abstract}
People who live with a disability are faced with the prospect of adjusting to the disability and its associated life experiences. Many people encounter negative and hurtful situations such as unemployment, lack of adequate resources, changes in relationships and social support, negative societal attitudes, bias, and discrimination, and so forth. Women with disabilities are subject to these same negative encounters, but they often experience several others based on their gender (i.e., higher rates of abuse, poverty, and financial independence). Given the likelihood that women may experience additional stressors with fewer supports in place, professionals must focus on the needs of women with disabilities and the sources of support. To meet this important need, two case studies are presented. The case studies are comprised of two women living with varying disabilities who completed Stuntzner and Hartley's. ${ }^{1} 10$-module resilience intervention. The women share information about their experience in working through the resilience intervention and in learning resilience-based skills to help them deal with their initial concerns and stressors. Both women reported decreases in depression and anxiety and increases in resilience and forgiveness as a result of working through the intervention.
\end{abstract}

Keywords: women with disabilities, resilience interventions for women, resilience case studies, resilience, resilience cultivation
Volume 5 Issue 4 - 2020

\author{
Susan Stuntzner,' Angela MacDonald, ${ }^{2}$ \\ Jacquelyn A Dalton ${ }^{3}$ \\ Student Success Center, School of rehabilitation counseling and \\ services, Southwestern Oregon Community College, University \\ of Texas Rio Grande Valley, USA \\ ${ }^{2}$ Adult Outpatient Services, Frontier Behavioral Health, USA \\ ${ }^{3}$ Clinical Rehabilitation \& Clinical Mental Health (CRCMH) \\ Counseling Program, East Central University, USA
}

Correspondence: Susan Stuntzner, Student Success Center, School of rehabilitation counseling and services, Southwestern Oregon Community College, University of Texas Rio Grande Valley, USA, Tel (54I) 888 -1578, Fax 54I-888-723I, Email susan.stuntzner@socc.edu, susan.stuntzner@utrgv.edu

Received: August 03, 2020 | Published: August 17, 2020

\section{Introduction}

Disability is an experience that forever changes a person's life and that of loved ones and families. ${ }^{2}$ Depending on the type of disability and its associated functional limitations, the disability can affect a person's mobility, cognition, mental faculties, emotions, independence, hearing, vision, self-care, dexterity, and peripheral feeling (i.e., sense of touch). Disability is also an experience that impacts various parts of peoples' lives. More specifically, people encounter situations that are related to the presence and functionality of the disability. Disability-related changes sometimes include underemployment or lack of employment, health insurance concerns, loss or alterations of social support and relationships, independence, negative societal attitudes and bias, and personal/attitudinal barriers. Several of these experiences occur regardless of the specific type of disability or a person's age and gender. Yet, there appears to be less information, research, and focus on the needs and coping abilities of women disabilities. There also appears to be more barriers and less support for women with disabilities experiencing such situations.

Understanding the experiences of women with disabilities is vital and an important part of the research. Disability statistics among women with disabilities indicate that women comprise a significant segment of people with disabilities. More specifically, according to the Centers for Disease Control and Prevention, ${ }^{3} 61$ million or $26 \%$ of the population in the United States is comprised of people with living with a disability. Within this 61 million, 36 million, or $59 \%$ are women with disabilities. ${ }^{4}$ Statistical data indicate that $44 \%$ of these women are 65 years or older. ${ }^{5}$ Some of this is related to the aging process and physical conditions such as arthritis. ${ }^{6}$ Globally, statistics tend to vary from country to country. Yet, data suggests that at least $15 \%$ of the global population (i.e., 1 billion people) lives with a disability ${ }^{7}$ and the majority of these are women. Furthermore, it is anticipated that these numbers will continue to increase given that people are living longer and women outlive men throughout the life span. ${ }^{8}$ Complicating matters is women typically experience more decline with age than men, are less likely to recover from disability, and live alone more frequently. ${ }^{9}$

\section{Issues experienced by women with disabilities}

Experiences of women with disabilities are scantly discussed throughout the literature. Much of the information that exists is dated and was conducted by women living with a disability or researchers interested in promoting the understanding and support needs of women with disabilities. ${ }^{10-13}$ Despite this lack of prioritizing women with disabilities throughout the research, scholars continue to inform and educate us about the needs and experiences of women with disabilities. ${ }^{8,14-17}$ Currently, women with disabilities continue to face several challenging and difficult experiences that often compound the experience of living with a disability and the coping process.

Similar to men with disabilities, women encounter unemployment/ underemployment, negative societal biases and perceptions, changes in social and family support, health insurance and financial concerns, environmental and architectural barriers, peoples' disregard for their personal boundaries, and lowered expectations, yet, at the same time, women with disabilities are exposed to additional layers of stress compared to their male counterparts. More specifically, women with disabilities experience a substantial amount of lowered societal expectations regarding their worth and abilities, ${ }^{13,15,18}$ and are viewed as "doubly- or triply stigmatized" due to living with a disability. This stigmatization contributes to women with disabilities being viewed as "one of the most disadvantaged groups of individuals". ${ }^{15}$ Furthermore, women with disabilities are at greater risk of (a) health discrepancies 
and inadequate health care, ${ }^{12}$ (b) less access to health care services and assistance,,$^{19}$ (c) not being able to afford health care services, ${ }^{20}$ (d)social isolation, ${ }^{15}$ (e) poverty, ${ }^{20}$ (f) unemployment and lowered financial health, ${ }^{20}(\mathrm{~g})$ limited career/employment opportunities, ${ }^{15}$ (h)abuse by partners and caregivers, ${ }^{21}$ (i) low self-esteem and selfworth, ${ }^{16,22}(\mathrm{j})$ internalization of projected negative messages regarding their body image and attractiveness, ${ }^{10}(\mathrm{k})$ negative societal messages about their worth, attractiveness, and value, ${ }^{23}$ and (1) being viewed as "damaged goods" 24 and asan unsuitable mother or life partner. ${ }^{25}$

Compounding the aforementioned negative experiences, barriers, and stressors is the notion that women with disabilities often experience bias and prejudice among health providers and in the provision of health care. ${ }^{26,27}$ As a collective, these negative issues and barriers inform us that women with disabilities are exposed to several barriers and stressors as a part of living with a disability. Similarly, professionals are reminded of the essential need to understand and assist women with disabilities, so they can increase their chances of reducing these barriers and improving their ability to cope more positively.

\section{Rationale for resilience intervention among women with disabilities}

Given what is known from the research, women with disabilities experience several stressors and societal barriers/attitudes as a part of living with a disability. Related is the professional literature that enlightens professionals to the reality that women with disabilities are under-served and under-recognized as an important area of focus within the research. Despite the lack of attention given to women with disabilities and their needs, we, the authors, wanted to address this gap in services, support, and research. More specifically, we wanted to help women with disabilities learn about resilience and resilience-based skills they could apply and integrate throughout their life. By learning about resilience and resilience-based skills and by having a choice in where and how to apply the skills they learned, women would have an opportunity to reduce the impact of negative experiences and improve their ability to cope with life stressors and challenging situations.

Women who participated in the resilience intervention were a part of a second pilot-study conducted using Stuntzner and Hartley's ${ }^{28}$ 10-module resilience intervention. The first resilience intervention study was utilized among a mixed group of men and women with disabilities. ${ }^{29,30}$ In the first resilience intervention study, Stuntzner and colleagues ${ }^{29,30}$ examined changes in anxiety, depression, resilience, and forgiveness before and following the conclusion of the 10-module resilience intervention. ${ }^{1}$ These same four areas (i.e., anxiety, depression, resilience, and forgiveness) were included as a part of the current study. Women who participated in the resilience intervention study were administered pre-tests, post-tests, and follow-up tests, two months later. Similar to the initial pilot studies, ${ }^{29,30}$ women who participated in the resilience intervention pilot study lived with varied disabilities and diagnoses. Some of these included Rheumatoid Arthritis, chronic pain, back/spinal injuries, fibromyalgia, depression, anxiety, Parkinson's disease and Posttraumatic Stress Disorder.

Two of the women who completed the resilience intervention from start to finish were selected to help illustrate the use of Stuntzner and Hartley's Resilience Intervention (SHRI) among women with disabilities. The cases presented below were selected because they help illustrate two women's experiences in learning about resilience and resilience-based skills and the insight they gained. Both case studies also depict women living with different disabilities and diagnoses. Understanding how the resilience intervention may be of benefit to women living with varying disabilities helps professionals better understand the importance and usefulness of helping women cultivate resilience.

\section{Overview of resilience intervention}

The two women, depicted in the following section, were exposed to Stuntzner and Hartley's ${ }^{1} 10$-module resilience intervention. The 10-modules covered throughout the intervention were "Resiliency and Personal Functioning, Outlook on Life, Perspectives on Locus of Control, Emotional and Mental Regulation, Coping Skills, Spiritual Beliefs and Practices, Compassion for Self and Others, Growth and Transcendence, Social Support and Family Cohesion, and Closing the Loop - Skills Learned". ${ }^{1}$

Each week, the women met one time, for 2. 5 hours, to learn about and practice a specific resilience-based skill. The resiliencebased skills were chosen as a part of the intervention because they represent skills cited throughout the literature as those that cultivate resilience ${ }^{31-35}$ and are also known to help people cope and adapt to a disability. ${ }^{29}$ The resilience-based skills learned included "resilience, attitude and outlook on life, locus of control, emotional and mental regulation, coping and problem-solving skills, spirituality, forgiveness, compassion, self-compassion, growth and transcendence, and personal/family support.". ${ }^{29}$ After learning about resiliencebased skills, the women had an opportunity to review the skills they learned and determine which ones they were going to continue using versus those they may not. They were encouraged to brainstorm new approaches and skills they might want to consider, even if the specific skill was not covered as a part of the intervention.

Within each module, the women were exposed to and completed several activities. During the initial stages of the intervention, the women were asked to select an area of their life to which they wanted to apply resilience and the content learned (i.e., personal, family, social support, employment, adjustment to disability; Stuntzner \& Hartley. ${ }^{1}$ Each module (i.e., the skill learned) was designed to (a) teach them content related to the presented skill, (b) help them selfassess their current habits and functioning concerning each skill, (c) explore potential barriers that may impede their progress in skill cultivation, (d) provide the women with applied exercises intended to promote skill enhancement, and (e) encourage additional skill practice throughout the coming week by creating personal goals and action plans. When the women returned the following week to work on the next skill, they were asked to share some of their discoveries about the skill practiced from the previous week.

The case studies discussed below are of two of the women who participated in a larger resilience intervention pilot-study conducted among a group of women with disabilities. ${ }^{1}$ These two were chosen to illustrate the value of resilience and resilience-based skills throughout their life and across varying types of disabilities. Our intent is by sharing these two women's experiences, professionals can better understand the value and importance of providing support to women with disabilities and helping them explore strategies to cultivate resilience. 


\section{Case descriptions}

\section{Case description I}

Amanda is a 56-year-old female who reported living with Posttraumatic Stress Disorder (PTSD) and depression for 21 years. She also stated that she has "bouts of vertigo and fibromyalgia."Amanda shared it is "hard for her to trust and make important decisions - both of which affect her emotionally, mentally, and physically." When asked about her day-to-day mood, Amanda used descriptors such as "anxious, stressed, and depressed more often than not." She went onto explain that her best coping skill was to remove herself from situations that she finds difficult or challenging.

At the start of the study, Amanda said that she wanted to learn how to be more peaceful with herself and calm when experiencing stress and stressful situations while participating in the resilience intervention study. During this same time, she also shared that she sometimes experiences frustration, depression, feelings of hopelessness, anxiety, changes or loss in social support, difficulty in forgiving herself, challenges in controlling her thoughts, and changes in how she sees herself. This information surfaced after she was asked to identify some of the experiences she has had following the disability or diagnosis. Many of these are similar to what is known about some peoples' experiences of living with a disability and have often been cited throughout the literature (i.e., depression, anxiety, difficulty forgiving, loss of social support, changes in self-perception; for a full review, see Stuntzner, 2008). ${ }^{36}$

Initial pre-test assessments found that Amanda was experiencing a severe amount of depression,elevated anxiety, and was having difficulty feeling resilient and forgiving towards the identified person chosen as a part of this study. Amanda began the study experiencing a high degreeof depression and anxiety and believes (based on selfreport) that people will negatively judge her. She also stated that she had difficulty connecting with others and felt thather disability prevented her from doing that. As Amanda began Module \#1, Resiliency and Personal Functioning, several of these concerns surfaced. More specifically, Amanda shared that she feels "anxious and fearful when she does not know how to handle a situation and does not know what to do." She also expressed that she is "afraid to take chances and has a hard time handling change." Related is the notion that she finds it "hard to be flexible and adaptive when situations are not going well." In addition, Amanda shared that she "withdraws or isolates rather than reaching out for help when going through difficult times."

At the end of Module \#1, Amanda was asked to identify some goals she wanted to work on and, in doing so, reflect on which parts of her life she wanted to apply resilience. She expressed an interest in developing a stronger support system, aligning her expectations with those that she has of others, and improving the relationship she has with herself. She stated that these goals would help her work on cultivating social support and improving her ability to self-advocate. She also indicated they would allow her to reach out and seek support rather than handle stress on her own and assist her with managing self-criticism. Furthermore, she explained that these areas are the ones she has the most trouble with and that trusting others and reaching out for support is hard for her, as well as not personalizing and internalizing less than ideal outcomes. Understanding these concerns and identifying areas people wish to improve is an essential feature of this intervention. Women were asked to reflect on their lives and decide which parts of life domains (i.e., personal life, social support, relationships, adjustment to disability, self-advocacy) they wanted to apply resilience and resilience-based skills. ${ }^{1}$

Module \#2, Outlook on Life, allowed Amanda to explore her attitude about life and situations she encounters. As a part of this module, we asked her to reflect on the people in her life and what they are like. We also queried about the "lessons" she could learn from situations that do not go as she would prefer, so that she may view them more positively. Of interest was how she wanted "to learn to trust herself more and determine whom she can rely on during tough times." This statement reinforced the importance of Amanda learning to trust herself and the people around her, as well as build a stronger social support system. Concerning the "lessons" she might learn, one area that surfaced was "learning that everything that happens is not about her." Learning to detach and not take events or the things people say personally is an important life skill and is relevant to people with disabilities. Due to the negative situations, women with disabilities encounter, some have a difficult time not internalizing other peoples' negativity ${ }^{37}$ Therefore, learning to identify the beliefs a person holds and the ways one interprets situations is an essential part of positive coping and adjustment.

In Module \#4, Emotional and Mental Regulation, Amanda further examined her thoughts, feelings, and behaviors and the way each of these are interrelated. Throughout, some of Amanda's responses were consistent with what she previously shared: (a) isolating and withdrawing when stressed, (b) having difficulty expressing and handling her feelings, (c) thinking about problems over and over, and (d) feeling uncomfortable around others. After this module, Amanda was asked to reflect on her thoughts and feelings and determine which of the two are the most challenging for her to moderate followed by the identification of goals to ameliorate what she finds challenging to self-regulate. Some of her goals centered around "the expression of feelings, not reacting to fear, and reaching out to meet new people" all of which are related to the initial areas she hoped to improve.

Module \#5 explored Coping Skills. Amanda examined the coping skills she used and the reasons she used them. In this module, women are were asked to identify those they used and how they helped them. If women used other ones not provided, they were asked to write those. Some of Amanda's skills were categorized as those that help her relax (i.e., going for a walk, listening to music, exercising, spending time in nature; Stuntzner \& Hartley, 2014). ${ }^{1}$ Others were identified as not helpful, but sometimes used (i.e., thinking about an issue a lot, feeling anxious, and isolating; ${ }^{1}$ Following this, she was asked to reconsider various parts of her life and identify those that caused her the most difficulty. Some of the areas noted where similar to those she initially shared at the start of the study (i.e., personal life, social support, self-advocacy). This information reinforced that Amanda continued to apply resilience-based skills to some of the initial concerns she reported at the start. Other features Amanda worked on were determining life areas to be improved, recognizing barriers that inhibited positive coping, and identifying new skills to be tried. By the end of this module, Amanda was encouraged to identify the coping skills she could use and develop to broaden her repertoire of resilience-based skills.

Module \#7, Compassion and Self-compassion, appeared to be an instrumental piece of Amanda's healing process, as we later learned at the end of the study. Throughout, Amanda learned about compassion and self-compassion, barriers that inhibit the cultivation of these skills, and applied exercises to help her understand the value 
of compassion and to visualize the compassionate person according to her perspective. ${ }^{1}$ As Amanda worked through this module, she shared that "she tends to judge herself harshly and realizes this is not something she needs to do."

After the study, Amanda gave her feedback as a part of the followup questionnaire. From the questionnaire, we learned that out of the resilience-based skills covered, the top three skills she found most useful were compassion and self-compassion, mental and emotional regulation, and coping skills. She went onto explain that compassion and self-compassion helped her realize that she judged herself more harshly than others. She also said she "now recognizes that we all do the best we can." Learning to not judge herself as harshly and to be more accepting of herself was a success as it was evidence of being less self-critical.

Amanda also stated that she found "the presented exercises (i.e., self-assessments, identification of barriers and strengths, exercises about one's disability, skill development activities, application exercises, and group sharing opportunities) and the whole program very helpful, comforting, and confirming." Another important realization was related to her resilience. When the study concluded, she was informed of the variables measured and was asked to reflect on her own experience and share if she felt that her life improved in any of the areas addressed. Her final comments referenced she felt "an increase in resilience and a decrease in self-judgment which she believed greatly lessened her anxiety and depression."

Amanda's change in functioning was also evident based on the measured improvements reported at the post-test and follow-up. Posttest scores showed a 31-point decline in depression (i.e., severe to no depression), a 27-point decrease in state anxiety and an 18-point reduction in trait anxiety, a 22-point increase in resilience, and an 88 -point increase in forgiveness. Two months later, during the followup assessment period, Amanda demonstrated that she maintained the change reported at post-test. Change scores revealed she experienced a 33-point reduction in depression, a 27-point decrease in state anxiety and a 33-point reduction in trait anxiety, a 27-point increase in resilience, and a 94-point increase in forgiveness. Scores from these assessments show that Amanda made positive strides in reducing anxiety and depression and in increasing resilience and forgiveness following the resilience intervention and maintained that improvement at the two-month follow-up.

\section{Case description 2}

Mindy is a 71-year-old female. Mindy reported living with Parkinson's disease. Mindy has a family history of Parkinson's and is concerned because she has an awareness of what may come. She also reported getting easily tired and stressed about the future, concerning the disability, as she does not know what to expect. Mindy described herself as "someone who used to be confident but now is tentative about walking and movement." She is fearful of falling. Mindy went onto share that "she is a worrier and this tendency makes coping more challenging." During the initial interview, Mindy shared that she feels "she is becoming less resilient as time goes on." More specifically, she indicated that she feels that in the past she dealt with things and life easier than she does now. She also stated that worry and anxiety are more prevalent, nowadays.

Early on Mindy was asked to describe her self and experiences since she first learned about having Parkinson's disease. She expressed feeling frustrated over not being able to do the things she used to do, being occasionally anxious, and experiencing changes related to the disability, and in her quality of life. More recently, she indicated having additional responsibilities at home that are likely causing more stress.

Before working through the 10-module resilience intervention, Mindy completed four assessments to establish a baseline for depression, anxiety, resilience, and forgiveness. Mindy's pretest scores indicated she was experiencing Borderline Clinical Depression, elevated state and trait anxiety, and was having a hard time feeling resilient, and had room to improve on forgiveness. As Mindy began Module \#1, Resiliency and Personal Functioning, she had the opportunity to learn about resilience and self-assess how resilient she believed herself to be. Some of the initial answers on the selfassessment were consistent with the self-reported information. For example, some of the responses suggested that she (a) feels anxious and fearful when approaching new tasks, (b) finds it challenging to be flexible and adaptable when life is not going well, (c) feels it hard to learn from difficult situations, and (d) worries when she does not know how to do something. ${ }^{1}$

As a part of Module \#1, Mindy was asked to review various life domains (i.e., personal family, social support, self-advocacy, adjustment to disability; Stuntzner \& Hartley) ${ }^{1}$ and reflect on those that are going well, as well as those that are not. This action step was requested as it serves as a means to help people ultimately decide which part (s) of their life they want to apply the resilience-based skills covered throughout the intervention. Next, Mindy was afforded the opportunity to (a) explore the skills she used to deal with difficult life events and determine which ones were and were not helpful, (b) identify any personal barriers she had with building resilience, and (c) learn about the benefits associated with resilience. After the module, Mindy talked about her goals and which parts of her life she wanted to improve. Those she chose were personal, financial, social support, and emotional well-being (i.e., less stress and worry).

Module \#2, Outlook on Life, gave Mindy a chance to review thoughts and beliefs held concerning life situations [i.e., "I lack confidence in my ability to solve problems"; Stuntzner \& Hartley]. ${ }^{1}$ More specifically, the initial self-assessment asked her to respond to statements focused on a person's "attitudes, expectations of life events, and methods used to approach life events". ${ }^{1}$ Some of Mindy's answers suggested that she might lack confidence in her abilities and the ways she copes with difficult life situations. Two other areas that surfaced were the importance of social support or lack of it and her attitude toward challenging life situations. Several of these responses were similar to what she initially reported before beginning the intervention.

Module \#6, Spiritual Beliefs and Practices, is where Mindy was introduced to forgiveness and encouraged to consider if it was relevant to her life and set of circumstances. Before working on forgiveness, Mindy was exposed to the idea of spirituality and was asked to discuss her personal views about this topic. Taking time to reflect and consider one's view of spirituality is important as people are likely to vary widely in what they believe, and in the ways, they implement meaningful practices. Another reason the discussion of spiritual beliefs and practices are important to address as a part of forgiveness is that these beliefs can help or hinder the forgiveness process. Therefore, we felt it was vital to spend time exploring each person's spiritual beliefs and practices while also introducing forgiveness. 
As a part of this module, Mindy indicated that she does not have "a belief in God or the hereafter, but she also stated that she tries to figure out in what way she is spiritual." Following the discussion of spirituality, Mindy learned about forgiveness and the benefits of forgiveness and completed an application forgiveness exercise (i.e., Forgiveness as a Means for Growth and Healing; Stuntzner \& Hartley). She concluded the module by participating in an activity where she was asked to review a list of spiritual practices and determine which she found most helpful. Mindy's top choices included (a) practicing visualization exercises, (b) committing to living life in a healthier way and being kinder to herself, (c) journaling, (d) practicing compassion towards herself and others, and (e) meditation.

Following Module \#6, Mindy participated in four more modules. Over the next few weeks, she learned about compassion and selfcompassion, growth and transcendence, and social support and family cohesion. The final module, Module \#10, Closing the Loop - Skills Learned, allowed Mindy to review the skills she learned and/or strengthened over the previous 9 weeks. She was asked to determine which skills were helpful, challenging but may be useful with more effort, and those not of interest. Related is the fact that she was encouraged to reflect on changes in her life compared to the start of the study. Such an activity helped prepare Mindy to share meaningful parts of the resilience-building experience with her peers, as well as develop a plan for continued practice following the intervention.

At the end of the study, Mindy was given a follow-up questionnaire to help provide additional insight into her experience and process as a woman who completed the intervention and the two-month followup. When asked about the most useful skills covered as a part of the intervention, Mindy indicated that forgiveness, resilience, outlook on life, and self-compassion were her top four choices. The skills she identified were covered in Modules 1, 2, 6, and 7. When encouraged to explain the reasoning behind her top two choices (i.e., forgiveness, resilience), she responded by stating, "Forgiveness has completely changed my feelings and behavior towards..... and resilience and forgiveness have allowed me to overlook things that were troublesome before." Mindy also indicated that learning about self-compassion was helpful, and this process helped her realize that approaching life this way is not selfish. Understanding this fact may have helped her embrace the therapeutic power it holds. Following, Mindy had the opportunity to share thoughts about how her life has changed with forgiveness, resilience, anxiety, and depression. She responded that she "feels more tender and forgiving.... and her anxiety has decreased. She believes this is a result of the skills she learned as a part of this experience."

Mindy's post-test and follow-up assessment scores were consistent with her self-report. Post-test change scores showed that she reduced her depression by 10 points, from Borderline Clinical Depression to no depression, and decreased her state anxiety by 15 points and her trait anxiety by 9 points. Post-test scores also showed that Mindy increased her resilience by 16 points and forgiveness by 50 points. Two months later, at follow-up, Mindy demonstrated additional reductions in depression and anxiety compared to her pre-test scores. More specifically, she experienced a 17-point reduction in depression, a 21-point decrease in state anxiety, and a 14-point reduction in trait anxiety. Mindy's follow-up scores in resilience showed a 12-point increase compared to her pretest scores and a 35-point increase in forgiveness. These scores suggest that she was not feeling depressed and very little anxiety by the conclusion of the study while continuing to experience a higher level of resilience and forgiveness compared to the start of the study.

\section{Discussion}

Illustrated above were two case studies of women living with a disability who participated in Stuntzner and Hartley's 10-module resilience intervention. ${ }^{1}$ Both women were part of a larger study conducted among women living with various disabilities (i.e., Rheumatoid Arthritis, chronic pain, back/spinal injuries, fibromyalgia, depression, anxiety, Parkinson's disease, and Posttraumatic Stress Disorder). As a part of the intervention, Amanda and Mindy met once a week for 2.5 hours and learned a specific resilience-based skill followed by continued practice throughout the week. Each skill built upon the foundation and learning that occurred the week before. The 10 skills they explored were "resilience and personal functioning, attitude and outlook on life, locus of control, emotional and mental regulation, coping skills, spirituality and forgiveness, compassion and self-compassion, growth and transcendence, and social and family support". ${ }^{29}$ Following these skills, Amanda and Mindy reviewed all of the skills they learned and how the skills impacted their life, conveyed their personal experiences throughout the resilience-building process, and developed a personal plan for continued practice.

Each module (i.e., topic) was structured so that they learned specific information about each skill before participating in module exercises. Each module provided them with opportunities to (a) selfassess their habits and current functioning in each area, (b) explore benefits and barriers of each skill, (c) apply the skill to their chosen life domain, (d) work through applied exercises designed to help with skill cultivation, and (e) create a weekly personal goal and action plan. The personal goal and action plan were used to give Amanda and Mindy a chance to apply what they learned each week and further strengthen the presented resilience-based skill.

Amanda's story, Case Description \#1, is one of a woman living with Posttraumatic Stress Disorder and depression for over two decades. At the start of the study, she shared that it was hard for her to trust, make decisions, view others as not judging her, and often felt anxious, stressed, and depressed. From the outset, Amanda reported that she wanted to "figure how to live a more peaceful life, feel less overwhelmed, and be less stressed when going through difficult situations."Amanda's initial assessment scores were consistent with what she initially reported as they indicated she had a severe amount of depression, elevated anxiety, and was having a hard time feeling resilient and forgiving towards the person she identified as committing a hurtful offense. Each of these can contribute, directly or indirectly, to a person feeling anxious, depressed, distrustful of others, overwhelmed, and not at peace with one's life.

In Module \#1, Resiliency and personal functioning Amanda learned about resilience, self-assessed her own ability to be resilient and cope with difficult life events, chose one life domain to which she would apply resilience and resilience-based skills, explored the benefits and barriers of resilience cultivation, and created a personal action plan. The action plan helped Amanda identify some goals she wanted to work on, as well as which part of her life she wanted to focus on as she learned various resilience-based skills. As Amanda worked through this module, several of her initial reported concerns surfaced (i.e., feeling anxious and fearful, being stressed when she does not know what to do). After Module \#1, Amanda identified some goals she wanted to work on as a part of the intervention process. She 
stated that she wanted to (a) build a stronger social support system, (b) right-size her expectations of herself and others, (c) improve her ability to self-advocate, and (d) develop a better relationship with herself. By working on these areas, Amanda stated that these goals would help her seek out support, reduce the pressure she puts on herself, and assist her in managing self-criticism. She also indicated that they could help address her distrust of others and assist her in not internalizing difficult situations.

Amanda proceeded through the modules in the order they were presented. Modules $2-4$ focused on a lot of peoples' attitudes, perceptions, and beliefs about their ability to influence and control desired outcomes, and mental and emotional regulation. In sum, they taught people about the power and influence of their thoughts and emotions, and how these two are related and influence the choices made. In Module \#2, Outlook on Life, Amanda stressed the importance of learning to trust her self and deciding whom she can trust in times of difficulty. She reiterated that it was vital "she not take everything so personally or think that what goes wrong is about her."

Module \#4, Emotional and Mental Regulation, was one Amanda rated of higher importance and value. Throughout this unit, she learned, more in-depth, how thoughts and feelings can positively or negatively affect us. She explored her ability to regulate her thoughts and feelings and assess the way she behaves when going through difficult life events. Amanda identified strengths and challenges she experienced with emotional and mental regulation, learned about the power of negativity and self-sabotage, and developed skills to help her regulate her thoughts and mood. Some of the goals she identified she wanted to work on throughout the week focused on expressing her feelings, not reacting to fear, and reaching out to meet new people rather than self-isolate.

Module \#7, Compassion for Self and Others, was the one Amanda rated as the most helpful in her process of learning to be more resilient. Throughout this module, Amanda learned about compassion and selfcompassion and had an opportunity to complete a self-assessment on how compassionate she is towards herself and others following the disability. Self-assessment statements focused on compassion towards oneself and others, and changes in compassionate attitudes or feelings because of the disability. ${ }^{1}$ Following, Amanda learned about compassion/self-compassion benefits and barriers, practiced visualizing the compassionate person according to her perspective, generated a list of self-compassionate behaviors, and worked on applying self-compassion to the experience of living with a disability. ${ }^{1}$

Following the 10-module resilience intervention, Amanda gave feedback about her experience, the skills she found most helpful, and information about how she saw her life improve. She rated selfcompassion/compassion, emotional regulation, and coping skills as the three skills she found most helpful in learning to be resilient. As a collective, she stated that "she found the whole program very helpful, comforting, and confirming and that she discovered forgiveness was a factor in developing the life skills she has and continues to develop." She also shared that she "feels her resilience has improved greatly as she is not as judgmental of herself.....And, as a result, her anxiety and depression have greatly lessened." Findings from the post-test and follow-up assessments support much of her self-reported changes. Both series of assessments demonstrated that she experienced a reduction in depression and anxiety and an increase in resilience and forgiveness.

Mindy's story, Case Study \#2, is one of a woman living with
Parkinson's disease and adjusting to the physical changes she experiences because of it and her anxiety and fear of the unknown. Early on, Mindy shared that she was "worried about the future because she witnessed her mother living with Parkinson's disease." Because of this, "she is aware of what may come, and these potential changes, along with the physical changes she has already experienced, cause her stress and anxiety."She shared that she feels "her increased stress may interfere with or exacerbate her Parkinson's disease and that the stress might accelerate the disease." Beyond her coping and adjustment process, Mindy talked some about the additional responsibilities and stressors she was facing in her personal life (i.e., becoming a caregiver). For these reasons, it was important for Mindy to decrease her anxiety and worry and build confidence in her ability to cope. Mindy's initial pre-test assessments suggested that she was having some challenges related to how she was feeling and coping. Her pre-tests assessments showed that she was experiencing Borderline Clinical Depression and elevated anxiety, not feeling resilient, and had some room to improve on forgiveness.

In Module \#1, Resiliency and Personal Functioning, Mindy learned the same information and completed the exercises mentioned above in the case of Amanda (i.e., learned about resilience, completed a self-assessment, chose one life domain to apply resilience). As Mindy proceeded through this module, much of what she shared was consistent with the concerns she initially reported (i.e., felt anxious when faced with new tasks, found it difficult to be flexible and adaptable). After Module \#1, Mindy indicated that her main goal was to reduce stress and that if she could reduce her stress, she felt this would help her be more resilient. As a part of this goal, she identified three smaller goals she wanted to try and improve: personal life and some of its associated financial aspects, social support, and worry and stress.

Module \#2, Outlook on Life, was one that Mindy rated highly in regards to being helpful. In this module, she learned how a person's outlook/attitude can affect one's perception of the disability and ability to cope. Next, she completed a self-assessment designed to help her recognize the attitudes, expectations, and strategies she held and the impact they have on her outlook on life. Following the selfassessment, Mindy participated in some activities designed to help her identify any changes in perspectives she may have experienced because of the disability and develop some skills to enhance her outlook on life. ${ }^{1}$

A part of what made this module more useful may have been the fact that Mindy had an opportunity to review and explore her thoughts and beliefs concerning specific life events and situations. She also had a chance to consider her beliefs and attitudes about living with a disability and if any of these have changed because of the disability. Another key feature that may have helped is the fact that as she learned more about her attitudes and beliefs, she was also encouraged to consider how these were affecting her personally and emotionally and if she wanted to consider changing any that did not help her. In the next module (i.e., Module \#3), some of the work initially started in this module was enhanced as she learned about locus of control and that the way people interpret situations can also affect how they feel and the choices they make.

Mindy rated forgiveness as the topic skill she found useful as a part of the intervention. Forgiveness was introduced and explored as a part of Module \#6, Spiritual Beliefs and Practices. Mindy learned about forgiveness following some initial content and exercises on 
the exploration of spirituality and spiritual practices. Spirituality was discussed before forgiveness because forgiveness is a topic that sometimes leads to the unearthing of peoples' spiritual and/or religious beliefs, as well as unresolved hurts or issues about their beliefs and practices. Exploring spirituality, as a part of forgiveness, is important because sometimes people "think" forgiveness is only for a "certain" kind of person (i.e., religious, believes in God). Yet, the reality is forgiveness is a helpful tool and skill regardless of a person's spiritual or religious beliefs. ${ }^{38}$ Understanding how spirituality and forgiveness can help, regardless of a person's beliefs, could have been an important part of Mindy's process, especially since she indicated that "she did not believe in God but was trying to figure out in what way she was spiritual....."

Mindy deepened her understanding of forgiveness when she explored the benefits of forgiveness and applied forgiveness to her life through an exercise called, "Forgiveness as a Means for Growth and Healing". ${ }^{1}$ Following this exercise, Mindy had an opportunity to review any spiritual practices she used or might consider as a part of spirituality and forgiveness. Some of her practices included: (a) using visualization exercises, (b) committing to living life in a healthier way and being kinder to herself, (c) journaling, (d) practicing compassion towards herself and others, and (e) meditation. By the time Mindy reached the end of the study, she indicated that forgiveness was a large part of her healing process. More specifically she stated, "Forgiveness has completely changed my feelings and behavior toward my spouse in a positive way.....resilience and forgiveness have allowed me to overlook things that were troublesome."

Similar to Amanda, Mindy had an opportunity to give feedback about her experience as a participant in the resilience intervention. Mindy rated forgiveness, resilience, outlook on life, and selfcompassion (i.e., Modules \#1, \#2, \#6, and \#7) as the most helpful, When asked about her collective experience, Mindy stated that "all of the exercises were helpful and informative and that having group sharing opportunities and being able to verbalize her thoughts and feelings helped her identify them."Findings from the post-test and follow-up assessments provided additional information about Mindy's change and experience. Both series of assessments demonstrated that she experienced a reduction in depression and anxiety and an increase in resilience and forgiveness. Of particular interest is that at the two-month follow-up, Mindy experienced an additional reduction in depression and anxiety compared to the conclusion of the 10-moduleintervention. Thus, at the end of the study, Mindy was not depressed and was much less anxious than at the start of the study which fits with her primary goal, “...to feel less stressed and not feel worried and anxious."

The two women described above were a part of a group resilience intervention study facilitated among women with disabilities. Previous resilience intervention studies facilitated among people with disabilities demonstrated that participants experienced reductions in depression and anxiety and increases in resilience and forgiveness following the conclusion of the intervention. ${ }^{29}$ Findings from these two case studies are similar in that the women experienced less depression and anxiety and increases in resilience and forgiveness at post-test and follow-up compared to the start of the intervention.

Information gathered as a part of these case studies provide new insights into the body of research. First, resilience and the cultivation of resilience may be helpful to women living with varying disabilities. As previously explained, Amanda and Mindy live with two different conditions. Amanda's was mental health related and physical (i.e.,
PTSD, depression, vertigo, and fibromyalsia), while Mindy's situation focused more on a physical disability (i.e. Parkinson's disease) compounded by anxiety and stress. Second, these cases shed light on the fact that long-term change in anxiety, depression, resilience, and forgiveness were either maintained or stronger than at the start of the study. Prior resilience intervention studies and case studies ${ }^{29,30}$ utilizing Stuntzner and Hartley's resilience intervention did not have long-term change data beyond that collected at post-test. Although this information is preliminary, it demonstrates that some people are able to maintain or improve functioning over a longer period of time. Third, from these case studies, researchers are reminded that people with disabilities identify and utilize different skills as a part of the resilience cultivation process. More specifically, Amanda's experience suggests that she found compassion, self-compassion, mental and emotional regulation, and coping skills as the most helpful. Mindy's experience indicates that she felt that the most useful skills she learned were forgiveness, resilience, outlook on life, and self-compassion. Due to the fact that these women varied in what they identified as the most valuable resilience-based skills, professionals learn that a variety of skills, topics, and approaches are an important part of the resilience-building process. Fourth, data change scores combined with Amanda's and Mindy's self-reports suggest that resilience cultivation might assist women with disabilities in reducing depression and anxiety. Although the case studies represent two women's experiences and cannot be generalized to the larger population, their reduction and anxiety and depression throughout the study can be used to further explore the effect resilience cultivation may have on peoples' mental and emotional functioning.

Professionals who work with women with disabilities are encouraged to consider resilience-based strategies. Women with disabilities face barriers and negative experiences similar to their male counterparts. However, women with disabilities are a group of individuals who also encounter additional layers of stressors (i.e., abuse, poverty, financial independence, lowered expectations) because they are women and often have less access to services and supports. Thus, professionals must consider strategies and approaches they may use to assist women in bolstering their personal and emotional functioning and confidence. One approach professionals can use is resilience and the cultivation of resilience-based strategies.

The aforementioned case studies illustrate some strengths that are worthy of mention. First, similar to prior case studies presented as a part of the resilience intervention pilot-testing process, ${ }^{29}$ these two women live with varying disabilities and have had different experiences regarding the length of time they lived with the disability and how it affected them. For example, Amanda lived with Post Traumatic Stress Disorder, depression, and fibromyalgia and lived with a disability for at least 21 years. Amanda found it hard to trust others, make decisions, moderate her thoughts and emotions, cope with change and uncertainty, and to not internalize criticism. Mindy lived with Parkinson's disease for about 2.5 years. Mindy indicated that she was struggling with how she felt and the amount of stress she was experiencing in coping with Parkinson's and its potential functional changes and personal parts of her life. Despite the varying disabilities and lengths of time to adjust to the disability and its associated changes, both women found the resilience skills and intervention of value in learning strategies to calm their emotions and reduce their stress.

Understanding how resilience and resilience-based interventions can assist women with disabilities is important as women have 
varying needs. The 10-module resilience intervention these women participated in was designed so that that they could learn specific skills, apply them to individualized parts of their life (i.e., personal, family, relationships, self-advocacy, employment; adjustment to disability), ${ }^{1}$ and specifically tailor them to their concerns and issues. For example, Amanda and Mindy learned the same skills and completed the same exercises, but they chose to apply the content to different parts of their life and in different ways. Amanda wanted to focus on social support, the relationship she had with herself, and self-advocacy. Mindy stated that she was primarily interested in working on reducing her overall stress. Within this goal, she indicated she wanted to focus on her personal life, social support, and reduce her worry and stress (i.e., coping and emotional well-being). Observing the ways Amanda and Mindy applied the content and skills was an important learning lesson. While our original intent is to help people choose one part of their life to which they apply resilience and resilience-based skills, Amanda and Mindy's experiences help us learn that people may find the process of value and help even if they recognize more than one area they want to work on.

Another strength is that the experience of learning resilience-based skills seemed to be useful to the women described in this paper. As indicated earlier, research conducted among women with disabilities is sometimes sparse as there are not ample studies that capture women's experiences. The case studies and content provided can help inform professionals of the need for further research and of the potential value of giving women with disabilities access to strengthbased approaches such as resilience-cultivation.

Two limitations exist as a part of this paper. The first is that the two case studies represent two women's experiences in learning resiliencebased skills as a part of Stunzner and Hartley's ${ }^{1}$ resilience intervention. Given that the sample size is small $(\mathrm{N}=2)$, the information presented may not be generalizable to other women's experiences. For this reason, combined with the sparsity of intervention research conducted among women with disabilities, further resilience intervention research is warranted and encouraged.

Second, the case studies are part of a larger resilience intervention study conducted among women with disabilities ${ }^{1}$ and to date, one other pilot-study utilizing) ${ }^{1}$ resilience intervention has been published. ${ }^{30}$ The initial pilot study did not include long-term change data so the follow-up data obtained and described as a part of these case studies is new information. Therefore, other resilience intervention studies do not have long-term data to compare the findings. Additional research is necessary to help substantiate the change measured as a part of long-term change.

\section{Acknowledgements}

None.

\section{Conflict of interest}

No potential conflict of interest relevant to this article was reported.

\section{References}

1. Stuntzner S, Hartley M. Stuntzner and Hartley's life enhancement intervention: developing resiliency skills following disability. Coos Bay, OR: Susan Stuntzner, Michael Hartley, \& Counseling Association of India. 2014

2. Stuntzner S. Resiliency and coping with disability: The family after. Ahmedabad, Gujrat, India. Counseling Association of India. 2015a.
3. Centers for disease control and prevention. Disability Impacts All of Us. 2019b.

4. Centers for disease control and prevention. Disability and health information for women with disabilities. 2019a.

5. Centers for disease control and prevention, National center on birth defects and developmental disabilities, division of human development and disability. disability and health data system. 2019.

6. Theis KA, Steinweg A, Helmick C, et al. Which one? what kind? how many? types, causes, and prevalence of disability among U.S. adults. Disability Health Journal. 2019;12(3):411-421.

7. World health organization.10 Facts on disability. Retrieved on July 22, 2020.

8. Lowe P, McBride HK. What factors impact the quality of life of elderly women with chronic illnesses: Three women's perspectives. Contemporary Nurse. 2012;41(1):18-27.

9. Morrissey S. Resources and characteristics of elderly women who live alone. Health Care for Women International. 1998;19:411 -421.

10. De Loach CP. Attitudes towards disability: Impact on sexual development and forging of intimate relationships. Journal of Applied Rehabilitation Counseling. 1994;25:18-25.

11. Hughes RB, Nosek MA, Howland CA, et al. Health promotion for women with physical disabilities: A pilot study. Rehabilitation Psychology. 2003;48(3):182-188.

12. Nosek MA, Hughes RB. Psychosocial issues of women with disabilities: The continuing gender debate. Rehabilitation Counseling Bulletin. 2003;46:224-233.

13. Olkin R. Women with disabilities. In: JC Chrisler, C Golden, editors. Lectures on the psychology of women. 4th edn. New York: McGrawHill. 2008;191-203.

14. Hassouneh-Phillips D, McNeff E. I thought I was less worthy": Low sexual and body esteem and increased vulnerability to intimate partner abuse in women with physical disabilities. Sexuality and Disability. 2005;23(4):227-240.

15. Nosek MA. Psychosocial issues of women faced by women with physical Disabilities. In: I Marini, MA Stebnicki. ediors. The psychological and social impact of illness and disability. 6th edn. 2012;117-134.

16. Parker MG, Yau MK. Sexuality, identity and women with spinal cord injury. Sexuality and Disability. 2012;30:15-27.

17. Stuntzner S. Self-compassion and sexuality: A new model for women with disabilities. ACA VISTAs, Summer Issue. 2014.

18. Stuntzner S. Stuntzner'sforgiveness intervention: Learning to forgive yourself and others. Coos Bay, OR: SusanStuntzner \& Counseling Association of India. 2015b.

19. Smith D. Disparities in health care access for women with disabilities in the US from the 2006 National Health Interview Survey (NHIS). Disability and Health. 2008;1:79-88.

20. Smith DL, Ruiz MS. Perceived disparities in access to health care due to cost for women with disabilities. The Journal of Rehabilitation. 2009;75(4):3-10.

21. Swedlund NP, \&Nosek MA. An exploratory study on the work of independent living centers to address the abuse of women with disabilities. The Journal of Rehabilitation. 2000;66(4);57-64.

22. Olkin R. What psychotherapists should know about disability. New York, NY: The Guilford Press.1999. 
23. Brodwin M G, Frederic PC. Sexuality and societal beliefs regarding persons living with disabilities. The Journal of Rehabilitation. 2010;76(4):37-41.

24. Hahn H. The social component of sexuality and disability: Some problems and proposals. Sexuality and Disability. 1981;4;220-233.

25. Addlakha R. How young people with disabilities conceptualize the body, sex, and marriage in urban India: Four case studies. Sexuality and Disability. 2007;25:111-123.

26. Au KW, Man D W. Attitudes towards people with disabilities: A comparison between health care professionals and students. International Journal of Rehabilitation Research. 2006;29:155-160.

27. Balter R. Psychotherapy with clients with physical disabilities. NYS Psychologist. 2006;8:29-33.

28. Stuntzner S, MacDonald A. Developing resiliency skills following disability: An intervention study for women with disabilities.] Unpublished data from a research study approved by the University of Idaho Institutional Review Board. 2014.

29. Stuntzner S, MacDonald A, Hartley M. Therapeutic effects of building resilience: An observation of two case studies. International Physical Medicine and Rehabilitation Journal. 2020(a):5(1):39-44.

30. Stuntzner S, MacDonald A, Hartley M, et al. Cultivating forgiveness, resilience, and positive change: A resilience intervention pilot study among persons with disabilities. International Physical Medicine and Rehabilitation Journal. 2020(b);5(2):67-73.
31. Black K, Lobo M. A conceptual review of family resilience factors. Journal of Family Nursing. 2008;14:33-54.

32. Dunn DS, Brody C. Defining the good life: Following acquired physical disability. Rehabilitation Psychology. 2008;53(4):413- 425.

33. Farley YR. Making the connection: Spirituality, trauma, and resilience. Journal of Resilience and Spirituality in Social Work, 2007;26(1):1-15.

34. Miller ED. Reconceptualizing the role of resilience in coping and therapy. Journal of Loss and Trauma. 2003;8:239-246.

35. Walsh F. Strengthening family resilience. New York, NY: Guilford Webb JR. Spiritual factors and adjustment in medical rehabilitation. Journal of Applied Rehabilitation Counseling. 1998;34:16-24.

36. Stuntzner S. Comparison of two self-study online interventions to promote psychological well-being in people with spinal cord injury: A forgiveness intervention and a coping effectively with spinal cord injury intervention. Dissertation Abstracts International. 2008.

37. Stuntzner S. Living with disability: finding peace amidst the storm. Ahmedabad, Gujrat, India. Counseling association of India. 2012.

38. Enright R, Fitzgibbons R. Forgiveness therapy: An empirical guide for resolving anger and restoring hope 2nd ed. Washington, DC: American Psychological Association. 2015. 